\title{
Região e etnorregião - um olhar a partir da realidade dos povos indígenas de Roraima, Brasil
}

\author{
Region and ethnoregion - a look from the reality of the indigenous peoples of Roraima, Brazil
}

\author{
Elionete de Castro Garzoni \\ Doutoranda em Geografia - UNICAMP-SP / Docente UERR/RR, Brasil \\ elionete.garzoni@yahoo.com.br
}

\author{
Maria Bárbara de Magalhães Bethonico \\ Doutora em Geografia - UFF-RJ / Docente UFRR-RR, Brasil \\ mbbethonico@insikiran.ufrr.br
}

\begin{abstract}
Resumo
O presente artigo apresenta uma discussão sobre a organização territorial dos índios de Roraima e sua configuração como etnorregiões. Roraima é o estado mais ao norte do Brasil, localizado na região Amazônica. Utilizando critérios como a localização, grupos étnicos (ou povos) estabelecem regiões próprias; em outra situação, instituições públicas (como as vinculadas à saúde) também fazem uma organização espacial, agrupando comunidades de forma a atender suas especificidades. Assim, as trinta e duas terras indígenas desse estado possuem organizações que se sobrepõem, cada uma delas a partir de sua lógica, mas que não implicam em conflito ou falta de identidade (pertencimento) para esses sujeitos. Nesse contexto, elegemos a Terra Indígena São Marcos, que abriga, principalmente, as etnias Macuxi, Wapichana e Taurepang, para discorrer sobre tal aspecto territorial. Esta terra indígena tem sua origem na área de uma Fazenda Nacional e hoje está dividida em três etnorregiões (Alto, Médio e Baixo São Marcos), definidas pela organização indígena que atende especificamente as demandas e necessidades das quarenta e quatro comunidades que ali estão inseridas. Destacamos a região do Alto São Marcos para apresentar alguns elementos, considerando que esta área está na fronteira do Brasil com a Venezuela e possui um constante fluxo de pessoas, além de abrigar a cidade de Pacaraima, conferindo a essa região uma dinâmica específica. Trata-se de uma pesquisa bibliográfica e documental que foi amparada pela experiência profissional das autoras que, na atuação como docentes de universidades da região, estabelecem contato direto com esses povos.
\end{abstract}

Palavras-chave: Etnorregiões, Indígenas, Roraima.

\begin{abstract}
This article presents a discussion about the territorial organisation of the indigenous people of Roraima and their configuration as ethno regions. Roraima is the northernmost state of Brazil, located in the Amazon region. Using criteria like localisation, ethnic groups (or peoples) they set their own regions; In other situation, public institutions (such as those linked to health) also make a spatial organisation, grouping communities in order to meet their specificities. So, the 32 indigenous lands of this state have overlapping organisations, each of them based on their own logic, but which do not imply in conflict or lack of identity (belonging) to these subjects. In this context, we choose the indigenous land São Marcos, which mainly shelter the Macuxi, Wapichana and Taurepang ethnic groups, to discuss this territorial aspect. This indigenous land originated in a communal farm area and today is divided into three ethno regions (Alto, Middle and Low St. Mark), defined by the indigenous organisation that attend specifically the demands and needs of 44 Communities that are inserted there. We highlight the region of Alto São Marcos to show some elements, considering that this area is on the border of Brazil with Venezuela and has a constant flow of people, besides sheltering the city of Pacaraima, giving this region a particular dynamic. This is a bibliographic and documentary research that was supported by the professional experience of the authors who, in acting as teachers of universities in that region, establish direct contact with these native peoples.
\end{abstract}

Keywords: Ethno regions, indigenous, Roraima. 


\section{INTRODUÇÃO}

O estado de Roraima tem sua organização espacial marcada pela presença de terras indígenas, que correspondem a 46,2\% de seu território. A demarcação de terras indígenas é um procedimento do Estado e refere-se ao reconhecimento do direito à terra, isto é, a um espaço necessário à reprodução física e cultural de grupos indígenas. Segundo Bethonico (2018, p. 299), este é um conceito jurídico, previsto em texto normativo emanado pelo Estado, onde "[...] a terra indígena tem seu conceito antropológico e cultural, mas a partir do momento em que está prevista na Constituição, passou a ser um conceito jurídico, trazendo consigo a necessidade de definição clara para que o próprio Estado possa operacionalizá-lo”. Os povos Macuxi, Wapichana, Taurepang, Patamona, Ingaricó, Yanomami, Ye'kuana, Waimiri-Atroari e Wai-wai habitam as trinta e duas terras indígenas de Roraima e, mesmo com a delimitação dos territórios definidos pelo Estado, fazem organizações próprias de seus espaços de vida, como são as etnorregiões.

O desempenho como docentes em universidades de Roraima que atuam diretamente com os povos indígenas (Universidade Estadual de Roraima e Instituto Insikiran de Formação Superior Indígena da Universidade Federal de Roraima) foi a base para a elaboração deste artigo, uma vez que essa situação permite às autoras participar de reuniões e assembleias, tanto nas comunidades quanto nas organizações indígenas. A experiência obtida com este convívio direto e com diálogos com membros comunitários têm permitido elaborar algumas reflexões sobre as diferentes formas de organização espacial e territorial construídas pelos próprios indígenas ou pelos órgãos e instituições que atuam junto a eles. Assim, este artigo se propõe a realizar um levantamento teórico sobre os conceitos de território, espaço e região a fim de que viabilizem a análise de dados secundários correlatos a tal organização espacial, como os distritos sanitários, as comunidades e as etnorregiões que existem no estado de Roraima. Destacamos na análise as etnorregiões devido ao modo como são definidas, pelos próprios índios, como forma de organização territorial que permite uma aproximação entre as comunidades e as lideranças conferindo participação por representação nas instâncias mais elevadas de decisão entre os indígenas. Trata-se, portanto, de uma forma de participação e controle territorial que confere unidade às terras indígenas e aos grupos étnicos nelas presentes.

\section{METODOLOGIA}

O estudo teve como ponto de partida a experiência e observações em atividades desenvolvidas junto aos povos indígenas do estado de Roraima. Essas observações geraram questionamentos, como a forma de organização espacial e/ou territorial desses povos e como constroem redes de comunicação e controle sobre o território. Esses contatos ocorreram em momentos de atividades acadêmicas e, a partir da preocupação em compreender essa dinâmica 
territorial, buscamos literatura que indicassem categorias geográficas que servissem de base para as discussões, como território, região e região cultural ou identitária, as quais buscamos relacionar com o que é chamado localmente de etnorregiões pelos próprios indígenas e lideranças.

Usamos como suporte dados secundários, coletados junto à Secretaria Especial de Saúde Indígena (SESAI) no seu Distrito Leste, que nos permitiram obter informações populacionais, do total de comunidades e dos polos base, unidade territorial utilizada pelo sistema de saúde indígena e que, também serve de referência para as populações que estudamos. O processo de homologação da Terra Indígena São Marcos, outra fonte documental, foi adquirido da Fundação Nacional do Índio (FUNAI) de Brasília, e permitiu compreender um pouco da história da área e a extração de alguns dados aqui utilizados. O conjunto de dados permitiu a elaboração de algumas imagens e, por fim, elegemos uma dessas etnorregiões para um detalhamento, indicando os objetos geográficos e algumas características específicas, possibilitando a aplicação das categorias escolhidas para a análise dessa realidade

\title{
3. REGIÃO E REGIÃO CULTURAL
}

Gimenez (1999), ao abordar o tema sobre o possível fim dos territórios e a ascensão da globalização como modelo econômico e social, defende que, diferente do que proclamavam alguns autores como B. Badie (que em livro de 1995 fala sobre o fim dos territórios), estes estão plenos e vigentes, tanto os territórios locais, os regionais quanto os estados nacionais. Possuem lógicas diferenciadas e específicas, o que os distingue, e passam por transformações na modernidade. Assim,

\begin{abstract}
Hay dos lecciones que, pese a todo. Debemos aprender de los teoricos neo-liberales de la globalizacion: 1) no todo es territorio y éste no constituye la única expresión de las sociedades; y 2) los territorios se transforman y evolucionan incesantemente en razon de la mundializacion geo-politica y geo-economica. Pero esto no significa su extinción. Los territorios siguen siendo actores económicos y políticos importantes y siguen funcionando como espacios estratégicos, como soportes privilegiados de la actividad simbólica y como lugares de inscripción de las "excepciones culturales" pese a la presión homologante de la globalización (GIMENEZ, 1999, p. 27).
\end{abstract}

Para Gimenez (1999) temos uma pluralidade de territórios que variam de acordo com a escala e nível em que foram historicamente constituídos e sedimentados, desde o local ao supranacional e, nesses extremos, encontramos escalas intermediárias como o município, a região e a nação. $\mathrm{O}$ autor alerta que essas escalas não devem ser percebidas como algo contínuo, mas como níveis imbricados entre si, quando o local está submetido ao municipal que, por sua vez, assim o está ao regional. No caso, podemos pensar as comunidades indígenas (nível local) como inseridas em outras escalas de organização territorial, como a terra indígena, a etnorregião, a região (como a Amazônica) e o Estado Nacional. Para o autor, territórios próximos são chamados de territórios identitários, como os espaços de vivência e com marcos naturais imediatos e concretos de um povo (rios, serras), entendidos como espaços comunitários; por outro lado, territórios mais vastos, como o 
Estado-Nação ou conjuntos supranacionais, são territórios da globalização e mais abstratos, distantes da vivência e da percepção subjetiva. A região seria o ponto de conjunção entre esses territórios.

A multiplicidade de olhares que são debruçados sobre a região (CORRÊA, 1998; GOMES, 2000; LENCIONI, 2003; BEZZI, 2004; entre outros) só não consegue ser mais ampla que as formas que a mesma toma na prática, em seus diferentes vieses. Ganhando novas abordagens à medida que evolui o pensamento geográfico, a categoria de análise geográfica região já foi registrada como aquela de maior dificuldade de definição/conceituação, e continua, na contemporaneidade, agregando novos olhares a partir das recentes relações estabelecidas no sistema capitalista.

Foi na década de 1970 que a geografia crítica se propõe a repensar o conceito de região sob o viés do materialismo histórico e da dialética marxista, onde a categoria foi é considerada "[...] sob uma articulação dos modos de produção [...] através das conexões entre classes sociais e acumulação capitalista" (CORRÊA, 1998). Lencioni (2003, p. 165) aponta que a influência marxista passa a considerar que a "parte do todo" a que a região corresponde não é mais "[...] concebida nem como uma totalidade lógica nem como uma totalidade harmônica. [mas] Foi concebida como uma totalidade histórica”, pois “[...] as injustiças e as desigualdades sociais do capitalismo eram evidentes e revelavam os limites da compreensão do mundo como um todo harmônico".

Essa consciência de que o mundo não se percebia como harmônico e equilibrado fez com que o tema do desenvolvimento desigual e combinado, bem como o do subdesenvolvimento fossem enfaticamente pesquisados (LENCIONI, 2003). Segundo Corrêa (1998) a lei do desenvolvimento desigual e combinado de Trotsky ofereceria um quadro teórico suficientemente amplo, que permitiria à região abranger as divergências de toda a superfície da Terra, uma vez que é uma lei da interpenetração dos contrários, onde são consideradas as diferenciações de fenômenos ocorridos em tempos diferentes, mas que coexistem no mesmo tempo e espaço presentes.

Tal leitura permitiria a compreensão de que a diferenciação de áreas foi consequência de um processo onde “[...] o aparecimento da divisão social do trabalho, da propriedade da terra, dos meios e das técnicas de produção, das classes sociais e suas lutas" aconteceu muito distante no tempo e no espaço, ressaltando a diferenciação intra e intergrupos (COORÊA, 1998). Para Santos (2006, p. 108) a especificidade de uma região decorre das diferenciações que acontecem no espaço a partir da distribuição diferenciada dos recursos que ali incidem, quer sejam “[...] o capital, a população, a força de trabalho, o excedente etc.”. Assim, a diferenciação dessas áreas, e entre elas, seria passível de alteração conforme a articulação entre tais recursos, a incidência de cada um deles e o a relação histórica de sua ocorrência numa área.

Outra abordagem a considerar sobre a região da geografia crítica ou de fundamentação marxista é dada por Haesbaert (2005), quando a considera a segunda "morte" da região, uma vez que permitiria a alguns imaginar “[...] pelo menos nos países centrais, uma homogeneização econômica 
de tal forma que as diferenças regionais desapareceriam”. Mas o próprio Haesbaert (2005) indica um contraponto a essa posição, quando outros autores marxistas consideravam o regionalismo enquanto luta social e não a região enquanto categoria de análise, para reconhecer a existência do fenômeno regional, citando o exemplo de Ann Markusen. Lencioni (2003) conclui que, apesar das contradições, as discussões da Geografia Regional sob a ótica marxista trouxeram grandes contribuições à Geografia, “[...] tendo sepultado a idéia (sic) de neutralidade da ciência e introduzido novas categorias de análise para o estudo regional".

Com o processo de globalização a relevância da escala regional passa a ser questionada, uma vez que está situada entre o 'local' e o 'global'. Para muitos autores a região perde o sentido enquanto diferenciação de áreas, em seu papel intermediário entre o singular e o universal, pois entendem que os níveis decisivos de análise pertencem ao 'local' e ao 'nacional' (LENCIONI, 2003). Haesbaert (1999) acredita que, na prática, o que temos são processos concomitantes de “[...] uma permanente reconstrução da heterogeneidade e da fragmentação via novas desigualdades e recriação da diferença em todos os cantos do planeta". O autor, que chama os processos de globalização de "[...] processos concomitantes de globalização e fragmentação", e entende que ao regressar "[...] às singularidades e ao específico ficam evidentes em correntes como o pós-modernismo e o pós-estruturalismo, denominações que evocam a crise social e de paradigmas em que estamos mergulhados, o que exige um constante questionamento de nossas proposições conceituais" (HAESBAERT, 1999, p. 16).

Ianni (1993 apud LENCIONI, 2003, p. 190) aponta novas incompatibilidades à medida que afirma que "[...] tudo que era principalmente regional, nacional e continental, agora é também, e principalmente, mundial". Para o autor, a sociedade global seria o panorama onde "[...] as condições de integração e antagonismo, alienação e emancipação, desenvolvem-se em escala ampla, acelerada, influenciando indivíduos, grupos, classes, etnias, minorias, sociedades e continentes".

Para Lencioni (2003), as diferenças regionais contrapor-se-ão ao processo que tende a anulálas, e os aspectos da realidade de determinada particularidade ficarão mais evidentes do que vistos anteriormente pela ótica global, onde a região volta a ser fundamental na análise espacial. Haesbaert (1999) entende que uma valorização do regional desponta no próprio cerne da globalização, “[...] como uma revalorização do singular, da diferença”. Mas alerta que outros autores entendem que a nova "regionalização" pode configurar um “[...] contraponto à globalização, via criação de grandes uniões comerciais".

Dessa forma, a recomposição da região como categoria de análise se coloca de forma decisiva, e o fato de seus movimentos de forma e conteúdo serem acelerados para acompanhar as exigências da pós-modernidade, não implicam que ela tenha desaparecido (LENCIONI, 2003), ainda que, em alguma medita, possam ter sido ressignificadas, como o caso das etnorregiões. 


\section{ORGANIZAÇÃO ESPACIAL DAS ÁREAS INDÍGENAS DE RORAIMA ${ }^{1}$}

Para Neira (1995) o conceito de território é essencialmente político e expressa certa soberania e autonomia para exercer o poder, ter domínios sobre terras e um sentimento de pertencimento particular. Envolve, também a ideia de identidade coletiva e domínio político. O território é, nesse sentido, resultado de um processo de construção social do espaço, com as ações e expressões que aportam a história e os valores de convivência, que combina herança cultural com características da contemporaneidade, isto é, territórios são espaços apropriados por pessoas que compartilham a vivência em um determinado período (FELIX, 2004).

Esses territórios, no caso aqui abordado, territórios indígenas, são organizados sob uma nova ótica, onde passam a usar a categoria (etno)região para estabelecer uma rede de contato e diálogo entre lideranças, organizações indígenas e comunidades. Para Felix (2004) o conceito de região no contexto cultural não apresenta uma delimitação pragmática como o Estado faz, mas refere-se a espaços que estão em constante processo de reconstrução, com fronteiras porosas e com possibilidades de alterações de acordo com a cultura e a história, isso devido ao fato de serem produtos das ações de quem as constroem.

No caso das etnorregiões existentes em Roraima, identificamos que sua delimitação ocorre a partir das organizações indígenas que precisam estabelecer redes de comunicação com as unidades menores ou os territórios identitários (as comunidades) e a forma encontrada foi através das representações regionais, os coordenadores regionais. Esses coordenadores são eleitos ou escolhidos, em momentos de assembleias, pelas comunidades em parceria com as organizações e precisam ter características específicas, como liderança, disponibilidade para o trabalho voluntário e uma boa relação com todos os lados da relação. Para Felix (2004, p. 15), uma região sociocultural não está reduzida a sua dimensão ecológica, demográfica, econômica ou política, mas também reveste-se de uma roupagem simbólica que "[...] ha ido confeccionando pieza por pieza em el curso del tiempo".

Hierro e Surrallés (2009), ao abordarem a questão da governança, destacam que o governo possui uma constitucionalidade que é oficial, homogênea e limitada por interesses do próprio governo central e, nessa lógica, é possível pensar na organização dos territórios indígenas pelos Distritos Sanitários Especiais Indígenas (DSEIs) e polos base, por exemplo, onde prevalece o acesso e as condições de trabalho da equipe contratada pelo Estado.

Por outro lado, esses autores apontam que a governança indígena se propõe a dar força à população local e expressa a necessidade de recuperar o controle territorial (recursos, decisões e relações) e, nesta situação, temos a organização por etnorregiões onde os próprios indígenas definem

\footnotetext{
${ }^{1}$ Aqui usamos o termo áreas indígenas no lugar de terras indígenas devido à existência de solicitações de demarcação de terras indígenas por parte de algumas comunidades, como o caso do Anzol (município de Boa Vista).
} 
seus limites e a forma como administram essas áreas. No caso de Roraima, essa gestão se dá a partir da eleição de um coordenador para cada etnorregião que tem a função de estabelecer a ligação entre as comunidades e a instância superior de decisão, isto é, as organizações a que estão vinculadas. Barabas (2003) aponta que um território é um espaço culturalmente construído por uma sociedade através do tempo, o que o diferencia de espaço (que tem maior alcance) e lugar. Para a autora podemos falar de etnoterritorialidade, que

[...] es un fenómeno colectivo que resulta de la histórica y múltiple articulación estabelecida entre naturaleza y sociedad en contextos de interacción específicos, tanto en la dimensión local (comunal), que es la más frecuentemente reconocida, como en la global (étnica) que supone cierto nivel de abstracción, ya que no se trata de territorios cotidianos. Desde mi perspectiva los etnoterritorios pueden comenzar a entenderse a partir de la singular conjunción de las categorias de tiempo, espacio y sociedad que se concretan en la historia de un pueblo en un lugar (BARABAS, 2003, p. 23).

Tanto os territórios locais quanto os globais possuem pontos geográficos e simbólicos, geralmente sagrados e especialmente significativos para o sujeito. Esses pontos especiais e referenciais, que são considerados emblemáticos, podem ser identificados como lugares, isto é, como centros a partir dos quais são traçados caminhos ou redes com estabelecimento de fronteiras comuns, sub-regionais e étnicas, diferentes de outras representações globais do espaço (BARABAS, 2003).

A região é uma categoria de análise espacial eficiente no que se refere à categorização, via diversos critérios que são acompanhados da dinâmica de seus objetos representativos. Nos processos classificatórios, a regionalização acontece com o uso de uma taxonomia que busca a individualização desses recortes espaciais delimitados por alguma característica comum ou uma lógica específica. A cultura pode, assim, ser representada em uma região que tem seus critérios de delimitação através de critérios culturais específicos de um grupo social, isto é, tem como referência as características ou códigos culturais. Pode, nesse contexto, abarcar apenas um dessas características, como por exemplo a gastronomia, as festividades, ou mesmo uma situação em que todos os códigos culturais são considerados (NETO; BEZZI, 2009).

A mesma lógica pode ser empregada às demandas da gestão, quando faz-se necessária determinada regionalização para o atendimento setorizado de políticas públicas, como saúde, educação, entre outras; ou ainda da organização política dos sujeitos sociais, em especial em grandes áreas administrativas. No caso de Roraima, conforme anteriormente mencionado, do total de seu território 46,2\% estão destinados às Terras Indígenas (TIs), que correspondem a $103.955 \mathrm{~km}^{2}$ (SEPLAN, 2013), distribuídos em 32 áreas já homologadas e uma em fase de identificação. Roraima ocupa a quinta posição no país e segunda na Região Norte, da Unidade da Federação com maior população indígena, com o total de 55.922 registros (IBGE, 2010). 
Diante deste cenário, assim como ocorre em outras áreas do Brasil, várias organizações espaciais são realizadas envolvendo as terras indígenas. Podemos citar, por exemplo, a área da saúde, que definiu os Distritos Sanitários Especiais Indígenas (DSEIs) que adotam critérios étnicos e culturais, geográfico, populacional e administrativo, visando um atendimento diferenciado e mais apropriado às comunidades.

Cada DSEI está organizado em polos base, isto é, unidades menores que agrupam algumas comunidades ou aldeias sendo que uma delas abriga a Equipe Multidisciplinar de Saúde Indígena (EMSI) que tem como tarefa realizar atendimentos às demais comunidades. Atualmente, existem 34 DSEIs no Brasil e 351 polos base, e dois deles estão em Roraima: o DSEI-Yanomami e o DSEILeste. Segundo dados da Secretaria Especial de Saúde Indígena (SESAI), o DSEI-Yanomami corresponde a uma terra indígena e atende os povos Yanomami e Ye'kuana, somando uma população de 25.486 habitantes, distribuídos em 323 comunidades (2017); enquanto o DSEI-Leste corresponde a 31 terras indígenas atendendo aos demais povos, que somam uma população de 47.260 (2016), distribuída em 316 comunidades.

As comunidades indígenas são também uma forma de organização territorial, uma vez que cada uma tem autonomia para tomar seus próprios rumos e uma estrutura de poder local, sendo os líderes o Tuxaua ${ }^{2}$ e Vice-tuxaua (eleitos em assembleia e com mandatos que variam de acordo com as decisões do grupo, que também pode decidir destituir tais lideranças do cargo, caso não estejam atuando conforme a perspectiva da comunidade). É possível considerar ainda uma conformação de território a partir da vinculação das comunidades a determinada organização indígena.

Em Roraima existem ainda organizações indígenas que tratam de temas ou segmentos específicos e que atuam em todas as comunidades, independente da composição étnica, como é o caso da Organização dos Professores Indígenas de Roraima (OPIRR) e da Organização das Mulheres Indígenas de Roraima (OMIRR), e outras que atuam nos aspectos políticos e produtivos (de gestão) das terras indígenas, como o Conselho Indígena de Roraima (CIR), a Sociedade de Defesa dos Índios Unidos de Roraima (SODIUR) ou a Associação dos Povos Indígenas da Terra São Marcos, além de organizações que atendem aos interesses de um grupo específico, como a Associação dos Povos Indígenas Wai-Wai (APIW), o Conselho do Povo Ingaricó (COPING) e a Hutukara Associação Yanomami ( HAY). As organizações que tratam dos aspectos políticos e produtivos constroem redes de comunidades que estão a elas vinculadas e, durante as assembleias anuais, discutem questões internas, problemas existentes nas comunidades e demandas a serem encaminhadas para instituições específicas, como educação, saúde, proteção das terras. Outra forma de organização espacial é a definição das etnorregiões. Em Roraima temos duas situações: uma seria quando uma mesma terra

\footnotetext{
${ }^{2} \mathrm{O}$ termo "tuxaua" é empregado pelos povos indígenas de Roraima para referir-se à liderança das comunidades. Equivalente a "cacique".
} 
indígena é dividida em etnorregiões, como é o caso da Terra Indígena Raposa Serra do Sol e Terra Indígena São Marcos; e outra, quando uma etnorregião que agrupa várias terras indígenas, normalmente pequenas áreas demarcadas, e que possuem poucas comunidades, como é o caso da Serra da Lua, onde predomina a etnia Wapichana, como pode ser verificado na tabela 1.

Tabela 1 - Etnorregiões do estado de Roraima.

\begin{tabular}{|c|c|c|c|}
\hline Etnorregião & Terras indígenas & Comunidades & Polos base \\
\hline Serras & Raposa Serra do Sol & 88 & 9 \\
\hline Ingaricó & Raposa Serra do Sol & 10 & 1 \\
\hline Surumu & Raposa Serra do Sol & 23 & 3 \\
\hline Baixo Cotingo & Raposa Serra do Sol & 44 & 4 \\
\hline Raposa & Raposa Serra do Sol & 42 & 4 \\
\hline Baixo São Marcos & São Marcos & 12 & 2 \\
\hline Médio São Marcos & São Marcos & 9 & 1 \\
\hline Alto São Marcos & São Marcos & 23 & 1 \\
\hline Amajari & $\begin{array}{c}\text { Anaro; Aningal; Ouro; Ponta da Serra; Ananás, Araçá, } \\
\text { Cajueiro; Santa Inês }\end{array}$ & 18 & 3 \\
\hline Murupu & Serra da Moça; Truaru & 5 & 1 \\
\hline Tabaio (antigo Taiano) & $\begin{array}{c}\text { Anta; Barata-Livramento; Pium; Boqueirão; Mangueira; } \\
\text { Raimundão; Sucuba }\end{array}$ & 11 & 2 \\
\hline Serra da Lua & $\begin{array}{c}\text { Canauani; Malacacheta; Moscou; Muriru; Tabalascada; } \\
\text { Bom Jesus; Jabuti; Manoá-Pium; Jacamim }\end{array}$ & 23 & 3 \\
\hline Wai-Wai & Trombetas-Mapuera; Wai-wai & 8 & 1 \\
\hline Yanomami & Yanomami & 323 & 37 \\
\hline
\end{tabular}

Fonte: Censo SESAI-DSEI-Leste (2016); Portal da Saúde (2017)³.

As etnorregiões agrupam comunidades que estão geograficamente próximas, sendo essa proximidade o critério utilizado. A relação das comunidades que integram uma etnorregião traz outras ideias que ajudam a compreender a complexidade dessa hierarquia. Para Gomes (2004) o conceito de comunidade está diretamente relacionado com o de comunalidade que tem conceitos de comunal, coletivo, complementariedade e integralidade como essenciais para sua existência. Para o autor, a comunalidade tem como características: i) a terra como mãe e território; ii) o consenso em assembleia para a tomada de decisões; iii) o serviço gratuito como exercício de autoridade; iv) o trabalho coletivo como um ato de recreação e, v) os ritos e cerimônias como expressão do comunal.

Para a discussão aqui apresentada, destacamos duas dessas características. A terra como mãe e território traz a relação de pertencimento, sendo esta terra a que "[...] nos pare, nos alimenta y nos recoge en sus entrañas" (GOMES, 2004, p. 368) e, por isso, não pode ter um proprietário. A terra

\footnotetext{
${ }^{3}$ Disponível em: <http://portalms.saude.gov.br/saude-indigena/saneamento-e-edificacoes/dseis>. Acesso: 18 mar. 2019. 
como território indica que cada elemento da natureza cumpre uma função necessária dentro do todo, com a noção de integralidade como um dos aspectos da vida. Essa integralidade considera a Terra como um espaço totalizador, sendo impossível separar seus elementos e esses elementos são igualmente importantes, os seres são iguais, inclusive nós humanos. Essa concepção elimina a superioridade humana frente aos demais seres naturais e o que nos diferencia é nossa capacidade de pensar, decidir, ordenar e usar racionalmente o que existe.

A segunda característica está na instância de tomada de decisões, que pressupõe a harmonia entre os seres vivos e cada habitante deve atuar positivamente em função da comunidade, isto é, para o bem comum, com direitos e obrigações para todos. Assim, “[...] una comunidad es un conjunto de familias que requiere de personas que cumplan con un papel paterno-materno superior al de los jefes de familia en particular: las cualidades de mando se deben combinar con la comprensión y dirección paternal" (GOMES, 2004, p.369). É a assembleia, composta pelos moradores (homens e mulheres) com seus filhos, é que tem o poder de nomear pessoas para darem o serviço anual às comunidades e esse serviço deve sair do coração, do sentimento de pertencimento próprio dos territórios.

A primeira instância de tomada de decisões é local, nesse sentido, a própria comunidade que possui domínio sobre o espaço que ocupa. Cada terra indígena tem sua área dividida pelas comunidades, sendo que estas são compostas de uma área central onde a maior parte dos moradores possui casas, além de outros objetos, como a escola, igrejas, o malocão (onde a comunidade faz as reuniões), o posto de saúde, dentre outros, além da área coletiva, onde fazem suas roças, criam animais e realizam atividades como a caça e pesca. A segunda instância de decisões, de caráter regional, está na figura do coordenador regional que, em reuniões das etnorregiões, encaminha as demandas das comunidades para as organizações e demais órgãos ou instituições públicas que podem contribuir ou solucionar os problemas das mais diversas ordens (educação, estradas de acesso, vigilância, produção, entre outros).

\section{A ETNORREGIÃO DO ALTO SÃO MARCOS - TERRA INDÍGENA SÃO MARCOS}

A Terra Indígena São Marcos foi homologada por meio do Decreto n. 312, de 29 de outubro de 1991, com uma área de 654.110 hectares nos municípios de Pararaima e Boa Vista, onde vivem 5.838 indígenas (ISA, 2018). Quanto aos grupos étnicos, as fontes apontam que são Makuxi, Wapixana e Taurepang, mas é sabido que, além desses, há residentes de outras etnias como, por exemplo, Tucano, Sapará, Pemon e Warao, sendo as duas últimas, decorrentes do recente processo migratório venezuelano. A partir de levantamento documental (Processo de Homologação FUNAI/BSB n. 0434/90) observamos que a história dos povos indígenas que habitavam a região que compõe atualmente a Terra Indígena São Marcos, passou por alterações territoriais oriundas das 
políticas indigenistas. A Fazenda São Marcos, com sede localizada na região próxima da confluência dos rios Tacutu e Uraricoera que são os formadores do rio Branco, foi criada no período de ocupação colonial do vale do rio Branco no século XVIII, visando reafirmar a ocupação portuguesa e garantir as fronteiras nacionais.

A Fazenda São Marcos foi identificada em 1878 (Relatório do Sr. Ministro da Fazenda) como a área que tem seu início na Serra de Pacaraima, ao norte e, os rios Branco e Tacutu ao sul na confluência dos dois rios, a leste com os rios Tacutu e Surumu e a oeste com os rios Branco ${ }^{4}$ e Parimé. A sua administração foi, inicialmente, de competência do Ministério da Fazenda e, em 1909 essa responsabilidade é transferida para o Ministério da Agricultura. O Serviço de Proteção ao Índio (SPI) assume a administração no ano de 1914 e, com sua extinção, a Fundação Nacional do Índio (FUNAI), que substituiu o SPI, recebe a administração da fazenda no ano de $1967^{5}$.

Atualmente essa terra indígena possui 44 comunidades, realidade bastante diferente do período em que foi homologada. No ano de 1988 foi realizado um levantamento onde constava a presença de 19 comunidades indígenas na área da Fazenda São Marcos, denominadas Roça, Perdiz, Bala, Bananal, Boca da Mata, Santa Rosa, Curicaca, Sabiá, Campo Alegre, Vista Alegre, Arai, Sorocaima I, Sorocaima II, São Marcos, Tigre, Mauixe, Milho, Darora e Lago Grande, onde habitavam 1.934 índios (FUNAI, 1990).

Alguns elementos foram introduzidos no espaço da área de São Marcos que conferiram uma outra configuração e atores. No ano de 1975 temos a instalação do Pelotão de Fronteira (Decreto n. 76.311), com intervenção do Estado e a presença do exército na linha de fronteira com a Venezuela. Outra alteração na área de fronteira é a existência da cidade de Pacaraima. No ano de 1981, o então Governador Ottomar de Sousa Pinto dirigiu um documento ao Ministro de Estado do Interior Mário David Andreazza, solicitando uma área de 999,99 hectares a ser desmembrada da São Marcos e destinada à ampliação da Vila de Pacaraima (GAB/Aviso n. 054/81 do Processo de Homologação). Ainda hoje temos a discussão sobre a definição fundiária da área urbana de Pacaraima, e se esta será excluída ou não da terra indígena ${ }^{6}$.

Considerando a configuração geográfica, a Terra Indígena São Marcos está dividida em três etnorregiões, a saber: a) do Baixo São Marcos, localizada no município de Boa Vista. Possui nove comunidades que praticam a agricultura, no formato de roças individuais e de autoconsumo, sendo o

\footnotetext{
${ }^{4}$ Acreditamos que essa delimitação definida pelo rio Branco é, na verdade, o rio Uraricoera que atualmente faz a delimitação dessa parte da Terra Indígena São Marcos.

${ }^{5}$ Memorial Informativo sobre a situação jurídica das tribos indígenas que habitam a Fazenda São Marcos no município de Boa Vista, Território Federal de Roraima, de 1 de novembro de 1973 e produzido por Tibério Cordeiro Tavares folhas 15 - 28 do Processo de Homologação FUNAI/BSB n. 0434/90.

${ }^{6}$ No caso de Pacaraima tem-se que a criação do município (Lei No 096, de 17/10/1995) é posterior ao Decreto $\mathrm{N}^{\circ} 312$, de 30/10/1991, que homologou a Terra Indígena São Marcos, gerando uma sobreposição e, por conseguinte, um conflito. A Fundação Nacional do Índio (FUNAI), por meio da Ação Cível Originária n 499-2/10, pede a retirada dos não índios da cidade; e atualmente há mais de 50 processos tramitando na Justiça Federal para tratar do caso.
} 
excedente da produção destinado à venda em pequenos comércios nas margens do rio Uraricoera ou na cidade de Boa Vista; b) do Médio São Marcos, no município de Pacaraima e possui nove comunidades. Uma característica dessa área é a dificuldade de acesso no período chuvoso (abril a agosto) e que fica parcialmente isolada. Essa situação afeta a relação com as áreas urbanas (Pacaraima ou Boa Vista) e fortalece a agricultura e a criação de gado e pequenos animais; e c) do Alto São Marcos que, pela presença de elementos específicos, apresenta o maior número de comunidades, no total de vinte e três, e com uma população que desenvolve a agricultura, mas que também possui forte vínculo com o comércio das duas cidades que a BR 174 interliga: Pacaraima e Boa Vista.

Na Figura 1 pode ser verificado tanto a Terra Indígena São Marcos em sua totalidade, à esquerda (em amarelo), bem como sua localização em Roraima e, à direita, o destaque à etnorregião do Alto São Marcos, objeto de detalhamento nesse estudo.

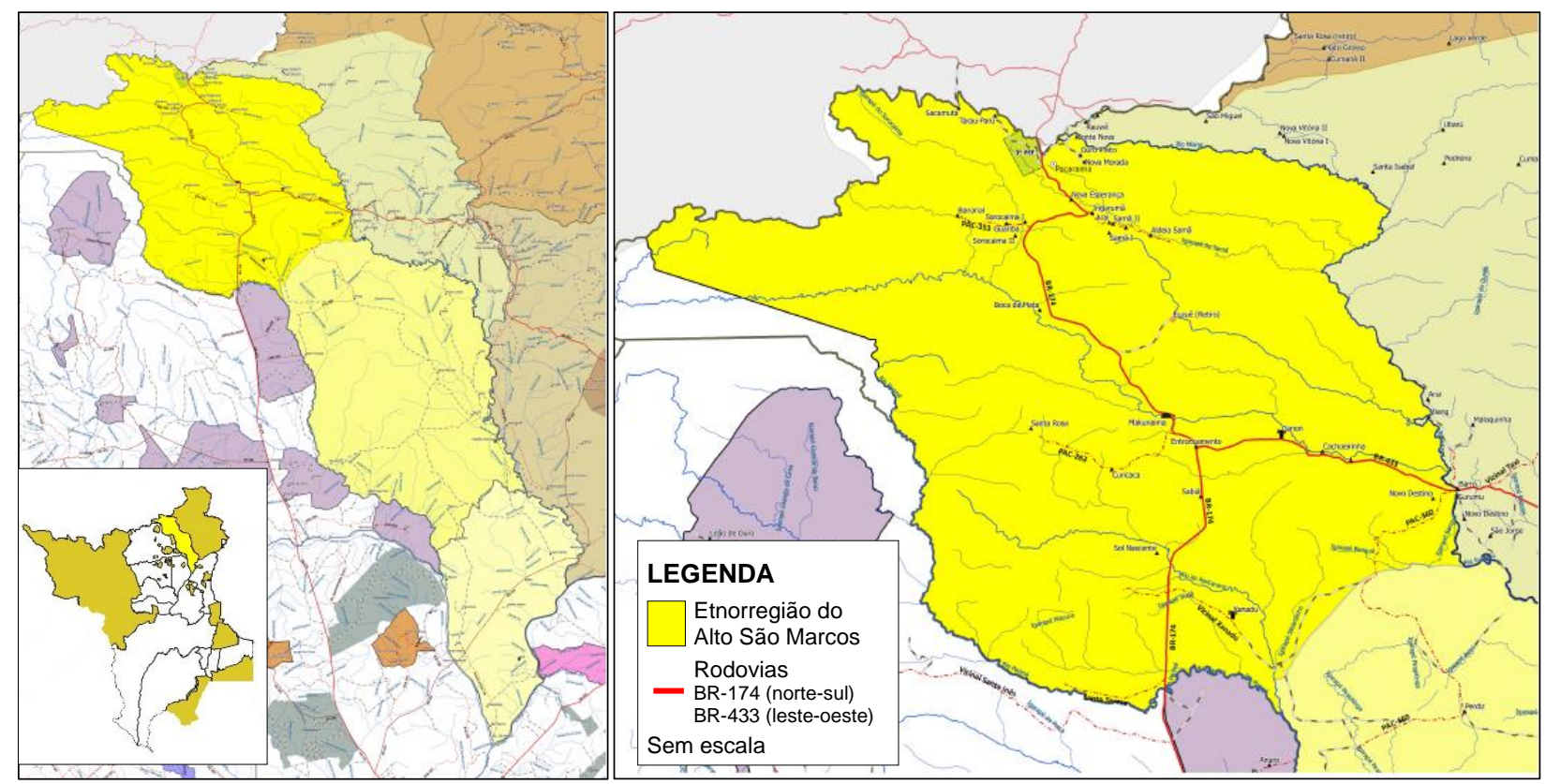

Figura 1 - Terra Indígena São Marcos (esquerda) e a etnorregião do Alto São Marcos (direita).

Fonte: Adaptado pelas autoras a partir de dados da FUNAI, 2018.

É possível verificar que a região do Alto São Marcos é cortada pela BR-174, que é o principal eixo viário do estado, ligando Manaus (AM) a Pacaraima (RR), passando pela capital Boa Vista. Implantada na década de 1970 “[...] sua construção fazia parte de um projeto geopolítico de integração territorial e de controle de fronteiras" (MAGALHÃES, 2008, p.162), além da ocupação da região amazônica, e teve um impacto significativo na mobilidade regional, que até então se dava unicamente por um modal fluvial. Magalhães (2008) registra ainda que o $6^{\circ}$ Batalhão de Engenharia e Construção (BEC), foi o responsável pela construção da estrada, mas somente em 1998 ela foi concluída, asfaltada e sinalizada. Para Lima (2014), essa empreitada colaborou para o crescimento populacional do estado, e colocou a rodovia como ponto de acesso estratégico. 
Apesar de sua relevância e dos benefícios que a BR-174 trouxe para Roraima, Oliveira (2007) discute sobre os conflitos ocorridos entre os povos indígenas locais, em especial os WaimiriAtroari, e os militares, os agentes da FUNAI e demais envolvidos no trabalho de abertura da estrada, provocando muitas mortes. Para o autor, trata-se de mais um caso de impactos socioambientais gerados pelos grandes empreendimentos visando a ocupação da região que registram um “"...] descaso com as populações locais que, em muitos casos, infelizmente, são vistos como uma barreira para o desenvolvimento" (OLIVEIRA, 2007, p. 58).

Esse cenário remete às observações de Duarte (1980), quando aponta que tratar a questão da regionalização e, por conseguinte, da integração regional, requer atenção à realidade tangente por parte do Estado, uma vez que são as diferentes formas de ação governamental no espaço regional que dirão o quanto o Estado promove o desenvolvimento regional, ou acaba dissolvendo regiões à medida que age sobre o espaço total. O Estado deve considerar simultaneamente dados estruturais e dados de conjuntura ao exercer seu papel na organização do espaço. Para Santos (1986, p. 183) o Estado tem seu papel afirmado numa "dinâmica global/local”:

[...] o Estado exerce pois um papel de intermediário entre as forças externas e os espaços chamados a repercutir localmente essas forças externas. O Estado não é, entretanto, um intermediário passivo; ao acolher os feixes de influências externas ele os deforma, modificando sua importância, sua direção e, ao mesmo, sua natureza. Isto significa que a reorganização de um subespaço sob a influência de forças externas depende sempre do papel que o Estado exerce.

Bezzi (2004, p. 53) chama atenção ainda para o fato de que o papel de agente de regionalização desempenhado pelo Estado considera, para além do caráter ideológico e/ou político, “[...] os diferentes estágios que o processo de reprodução do capital assume nos distintos recortes regionais", proporcionando maior ou menor grau de homogeneização entre eles.

No trecho da BR-174 que atravessa a etnorregião do Alto São Marcos, é também possível identificar alguns assentamentos humanos ao longo da rodovia, que vão da Comunidade Sabiá, ao sul, até a cidade de Pacaraima, ao norte; e, além desses, há diversas comunidades no 'interior' dessa área. Dessa forma, ao tomar o Alto São Marcos como uma etnorregião, tem-se que tais assentamentos configuram os lugares de atuação dos sujeitos sociais que ali residem e que interagem entre si e com os elementos, lugares e regiões externos a essa área. Buscando definir os tipos de interações passíveis de serem estabelecidos citamos Santos (2006, p. 90), quando afirma que:

Todos os lugares existem em relação com um tempo do mundo, tempo do modo de produção dominante, embora nem todos os lugares sejam, obrigatoriamente, atingidos por ele. Ao contrário, os lugares se diferenciam, seja qual for o período histórico, pelo fato de que são diversamente alcançados, seja quantitativamente, seja qualitativamente, por esses tempos do mundo. O tempo do mundo seria o tempo mais externo, abrangente de todos os espaços, independentemente de escala. 
Uma condição peculiar dessa área, dissonante das demais regiões do país, nas quais o ritmo acelerado e a permeabilidade ao meio técnico científico informacional é ampla, no Alto São Marcos o espaço-tempo da produção é diferente por não tratar de uma terra com valor de troca, mas sim com valor de uso. Configura-se, pois, como uma delimitação territorial de uma terra pública (da União) que não é universal, mas que atende a uma determinada finalidade, que é garantir a especificidade do modo de vida dos povos indígenas. Como propõem Santos e Silveira (2006, p. 30) ao discorrer sobre "os meios naturais", trata-se de um "[...] território caracterizado pelos tempos lentos, onde as diferenciações enraizavam-se na natureza e um tempo humano buscava timidamente ocupar os alvéolos de um tempo "natural"'. Essa conjuntura remete novamente à fala de Santos (2006, p. 108) sobre a proximidade (quiçá fusão) de região e lugar, quando estes definir-se-iam "[...] como funcionalização do mundo" e como meio pelo qual este seria empiricamente percebido.

Assim, ademais às demandas dadas pelo capital, como a aquisição de bens de consumo industrializados (desde comida e vestuário até celulares e automóveis), há nestes assentamentos, em particular nos indígenas, o lugar do coletivo e do ritmo diferenciado, como a caça, a pesca, a roça, a feitura do beiju e outros tantos elementos que colocam esses sujeitos sociais em outra posição em relação ao tempo do capital.

Da mesma forma, as relações estabelecidas entre eles (entre os assentamentos apontados) e entre eles e os assentamentos externos ao Alto São Marcos, indígenas ou não (considerando aqui, inclusive a relação com Boa Vista, enquanto capital e concentradora da oferta de bens e serviços para todo o estado de Roraima) são igualmente marcadas por outros ritmos e demandas, que vão desde os meios de se deslocar no espaço até as peculiaridades culturais da consolidação de tais relações. Não se pretende descartar aqui as influências do meio técnico científico informacional, dado que estão postas em âmbito generalizado; mas considerar que exercem influência diferenciada no tempo do fazer desses assentamentos, pela própria restrição do acesso, peculiar à região amazônica. Na mesma medida, não cabe descartar que parte desse fazer lento constitui consciente processo de resistência e autoafirmação identitária, haja visto as iminentes ameaças a esse modo de vida e ao que ele representa.

Little (2004) aponta um fator agravante no que tange às formas de propriedade social de povos tradicionais do Brasil, como é o caso dos povos indígenas, uma vez que têm os bens como coletivos, configurando o que o autor denomina "público", ao mesmo tempo em que são tutelados pelo Estado, ou seja, “[...] essa razão histórica introduz coletividades que funcionam em um nível inferior no plano do Estado-nação" (LITTLE, 2004, p. 259). Apesar disso, o autor propõe uma definição de territorialidade que considera “[...] o esforço coletivo de um grupo social para ocupar, usar, controlar e se identificar com uma parcela específica de seu ambiente biofísico, convertendo-a assim em seu "território"” (LITTLE, 2004, p. 253). 
No momento histórico vivido pela sociedade contemporânea, onde a quase totalidade das formas de apropriação do território perpassam a lógica do capital ou, mais veementemente, do neoliberalismo, não é estranho que as relações de coletividade e solidariedade estejam sendo colocadas em xeque, para dar lugar à individualidade ou à pseudo liberdade de escolha acenada pelas práticas neoliberais (DARDOT; LAVAL, 2016). Cabe, entretanto, aos povos indígenas a decisão pela manutenção de seus valores culturais, bem como os ajustes possíveis no cenário contemporâneo.

\section{CONSIDERAÇÕES FINAIS}

Os territórios podem ser diferenciados de acordo com a escala que os define, deslocando-se de uma escala local, como o território identitário, até territórios globais. A região serve de elo entre essas diferentes escalas, como observamos na situação dos povos indígenas de Roraima. A região está entre as categorias geográficas e tem sua importância ligada ao fato de que serve de base para a elaboração de teorias sobre o espaço de forma a expressar a essência de alguns fenômenos, como a forma de organização espacial decidido pelos indígenas de Roraima. Esses estudos geográficos são vitais para a ciência geográfica, contribuem e avançam qualitativamente na interpretação do real.

Nesse contexto, apresentamos algumas reflexões sobre diferentes formas que observamos na organização espacial dos povos indígenas dessa parte da Amazônia. Essa variedade atende a diferentes objetivos, seja de uma política indigenista, como a saúde ou as terras indígenas, seja pela demanda das próprias sociedades que aqui estão inseridas. Temos, assim, a organização por comunidades, pensadas aqui como territórios identitários onde os moradores possuem autonomia de definir situações específicas e que envolvem os moradores, os usos dos recursos naturais e outras necessidades; no atendimento a uma política indigenista, temos a divisão dos Distritos Sanitários Especiais Indígenas/DSEI, com duas representações em Roraima e que são subdivididos nos polos base, unidades menores que agrupam comunidades próximas e que facilitam o deslocamento das equipes de saúde. Acreditamos que essa dinâmica estabelecida pelos polos base atende mais ao Estado do que os povos indígenas, uma vez que em algumas áreas temos isolamento das comunidades, principalmente no período de chuva impedindo a circulação das equipes e deixando em situação vulnerável os moradores.

Discutimos, com maior detalhe, as etnorregiões que têm como critério primeiro a localização geográfica, e que são definidas pelas organizações indígenas a que essas comunidades são vinculadas. Entendidas como escala intermediária do território, a etnorregião se tornou o elo entre as comunidades (representadas pelo coordenador regional) e a organização indígena, permitindo que suas demandas tenham voz e sejam dirigidas para as instâncias que podem resolver problemas. Temos, assim, 14 etnorregiões em Roraima que abrigam todas as trinta e duas terras indígenas. Destacamos, nesse 
contexto, a etnorregião do Alto São Marcos para demonstrar que, mesmo sendo uma delimitação espacial definida pelos povos indígenas, estão vulneráveis às mudanças advindas de ações externas, normalmente dos governos, como é o caso da construção de rodovias.

As diferentes formas de organização das áreas indígenas indicam que existem várias necessidades e que esses povos buscam caminhos para resolverem seus problemas e o atendimento das demandas que são constantes, como a saúde, a educação, a produção, a preservação de áreas de caça e pesca e, também, questões políticas, de governança, situação que imprime uma autonomia na gestão de seus territórios.

\section{REFERÊNCIAS}

BARABAS, A. M. (Coord.). Diálogos con el territorio: simbolizaciones sobre el espacio en las culturas indígenas de México. Ciudad de México: Instituto Nacional de Antropología e Historia, 2003. 440p.

BETHONICO, M. B. M. Territórios e terras indígenas: uma breve reflexão a partir da Geografia. Revista de Geografia, Recife, v. 35, n. 2, p. 289-307, 2018.

BEZZI, M. L. Região: desafios e embates contemporâneos. In: SEI-Superintendência de Estudos Econômicos e Sociais da Bahia (Org.). Desigualdades Regionais. Série Estudos e Pesquisas. Salvador: Bigraf, 2004. 274p.

CORRÊA, R. L. Região e organização espacial. São Paulo: Ática, 1998. 93p.

DARDOT, P.; LAVAL, C. A nova razão do mundo: ensaio sobre a sociedade neoliberal. 1. ed. São Paulo: Boitempo, 2016. 413p.

DUARTE, A. C. Regionalização: considerações metodológicas. Boletim de Geografia Teorética, Rio Claro, v. 10, n. 20, p. 5-32, 1980.

FELIX, J. J. F. Reinventando la ciudadania: la construcción social de la democracia em la región Costa Montaña de Guerrero. 2004. 136 f. Tesis (Doctorado en Antropologia) - Centro de Investigaciones y Estudios Superiores em Antropologia Social, Ciudad de México, 2004.

FUNDAÇÃO NACIONAL DO ÍNDIO/FUNAI. Etnorregiões Indígenas do Lavrado de Roraima. Coordenação Regional da FUNAI em Roraima. Serviço de Gestão Ambiental e Territorial (SEGAT). Boa Visa, RR, 2018. Escala: 1:350.00.

FUNDAÇÃO NACIONAL DO ÍNDIO/FUNAI. Processo FUNAI/BSB - 28870, n. 0434/90 referente à Homologação da demarcação topográfica da Área Indígena da Fazenda São Marcos, localizada no município de Boa Vista, Estado de Roraima sob a jurisdição da ADR de Boa Vista/5a SUER.

GIMENEZ, G. Território, cultura e identidades: la región sócio-cultural. Estudios sobre las culturas contemporáneas. Epoca, Colima, v. 5, n. 9, p. 25-57, 1999. 
GOMES, F. D. Comunidad y comunalidad. In: Diálogos en la acción - segunda etapa. DGCPI, 2004. p. 365-373. Disponível em: <http://rusredire.lautre.net/wp-content/uploads/Comunidad.-y0comunalidad.pdf>. Acesso em: 26 mar. 2018.

HAESBAERT, R. Região, diversidade territorial e globalização. Revista GEOgraphia, Niterói, v. 1, n. 1, p. 15-39, 1999.

HAESBAERT, R. Morte e Vida da Região: antigos paradigmas e novas perspectivas da Geografia Regional. In: SPOSITO, E. (Org.). Produção do Espaço e Redefinições Regionais: a construção de uma temática. Presidente Prudente: UNESP, FCT, GASPER, 2005. p. 9-33.

HIERRO, P. G.; SURRALLÉS, A. Antropologia de un derecho: Libre determinación territorial de los pueblos indígenas como derecho humano. Copenhague: IWGIA: Copenhague, 2009. 221p.

IBGE. Censo Demográfico 2010. Disponível em: <https://ww2.ibge.gov.br/ home/\#redirect>. Acesso em: 05 nov. 2017.

ISA. Instituto Socioambiental. Terras Indígenas. Banco de dados online. Disponível em: <https://terrasindigenas.org.br/>. Acesso em: 10 out. 2018.

LENCIONI, S. Região e Geografia. 1. ed. São Paulo: EDUSP, 2003. 224p.

LIMA, M. K. F. BR-174: a expedição Calleri (1968-1970). 2014. 59 f. Monografia (Trabalho de Conclusão de Curso em História, Universidade Federal de Roraima, Boa Vista, 2014.

LITTLE, P. E. Territórios sociais e povos tradicionais no brasil: por uma antropologia da territorialidade. In: OLIVEIRA, L. R. C.; TEIXEIRA, C. C.; FILHO, W. T. Anuário Antropológico/2002-2003. Rio de Janeiro: Tempo Brasileiro, 2004, p. 251-290.

MAGALHÃES, M. G. S. D. Amazônia o extrativismo vegetal no sul de Roraima: 1943 - 1988. 1. ed. Boa Vista: Editora UFRR, 2008. 234p.

NEIRA, C. M. Comunidades y territorios Lafkenche, los mapuche de Rucacura al Moncul. 1. ed. Temuco: Instituto de Estudios Indígenas, 1995. 124p.

NETO, H. B.; BEZZI, M. L. A região cultural como categoria de análise de materialização da cultura no espaço gaúcho. RA'E GA, Curitiba, n. 17, p. 17-30, 2009.

OLIVEIRA, R. S. As transformações na organização espacial do Estado de Roraima: uma conversa inicial a partir da BR-174. Revista Acta Geográfica, v. 1, n. 1 p. 45-65, 2007.

RIBEIRO, A. C. T. Regionalização: fato e ferramenta. In LIMONAD, E.; HAESBAERT, R.; MOREIRA, R. (Orgs.). Brasil, século XXI - por uma nova regionalização? Agentes, processos e escalas. São Paulo: Max Limonad, 2004. p. 194-212.

SANTOS, M. Por uma geografia nova: da crítica da geografia a uma geografia crítica, 1986. 288p.

SANTOS, M. A natureza do espaço. Técnica e tempo, razão e emoção. São Paulo: EDUSP, 2006. $258 \mathrm{p}$.

SANTOS, M.; SILVEIRA, M. L. O Brasil: território e sociedade no início do século XXI. Rio de Janeiro: Record, 2005. 473p. 
SEPLAN. Secretaria Estadual de Planejamento e Desenvolvimento de Roraima. Posição e Extensão. 2013. Disponível em: 〈http://www.seplan.rr.gov.br/site/index. php?governode roraima=estatisticas〉. Acesso em: 05 out. 2017.

Trabalho recebido em 12/07/2019

Trabalho aceito em 13/07/19 